\title{
Two Cases of Malignant Pheochromocytoma Treated with Cyclophosphamide, Vincristine and Dacarbazine in a Combined Chemotherapy
}

\author{
TAKaO NOSHIRO, Hidemaru HONMA, KaZUMASA SHIMIZU, TAKU KUSAKARI, \\ TOSHIYA WATANABE, Hiroyoshi AKAMA, SATORU SHIBUKAWA, WAKaKo MIURA, \\ KEISHI ABE, AND YUKIO MIURA*
}

The Second Department of Internal Medicine, Tohoku University School of Medicine, *Department of Informatics on Pathophysiology, Tohoku University Graduate School of Information Science, Sendai 980-77, Japan

\begin{abstract}
Two patients with malignant pheochromocytoma were treated with a combination chemotherapy regimen consisting of cyclophosphamide, vincristine, and dacarbazine (CVD). With the first few cycles of the treatment, one patient, a 29-year-old man had a marked improvement of clinical symptoms and decreases in tumor size and catecholamine levels in plasma and urine. He had been in a clinically stable condition for 18 months but died 34 months after starting of this treatment because the CVD regimen became ineffective and rapid growth of the metastatic tumors occurred. The other patient, a 35-year-old man showed no significant change in tumor size but decreases in hormonal levels in response to CVD regimen. The patient has been in clinically stable condition in a follow-up of 24 months. The combined chemotherapy with CVD appears to be effective for advanced malignant pheochromocytoma.
\end{abstract}

Key words: Malignant pheochromocytoma, Catecholamine, Cyclophosphamide, Vincristine, Dacarbazine (Endocrine Journal 43: 279-284, 1996)

PHEOCHROMOCYTOMA in approximately 10$20 \%$ of all patients is malignant [1-4]. Treatment of malignant pheochromocytoma is based primarily on surgical resection, but most malignant pheochromocytomas are unresectable and radiation therapy including administration of a large dose of ${ }^{131}$ I-metaiodobenzylguanidine ( ${ }^{131} \mathrm{I}-\mathrm{MIBG}$ ) [5-7], chemotherapy, or both have been selected for the treatment of these rare tumors.

Effective chemotherapy for malignant pheochromocytoma has not been established in spite of many attempts with single or combined cytotoxic therapy [8-10]. But Averbuch et al. [11] recently

Received: October 11, 1995

Accepted: February 6, 1996

Correspondence to: Dr. Takao NOSHIRO, The Second

Department of Internal Medicine, Tohoku University School of Medicine, 1-1 Seiryo-cho, Aoba-ku, Sendai 98077, Japan reported that a combined chemotherapy with cyclophosphamide, vincristine and dacarbazine (CVD) was effective for the treatment of malignant pheochromocytoma. This combination chemotherapy regimen was based on the treatment of advanced neuroblastoma, a tumor with several pathological and biochemical features in common with malignant pheochromocytoma [12, 13].

In this report, we present two cases of malignant pheochromocytoma treated with a combined chemotherapy with CVD.

\section{Case Reports}

\section{Case 1}

As shown in Fig. 1, a 29-year-old man had an extra-adrenal pheochromocytoma surgically re- 

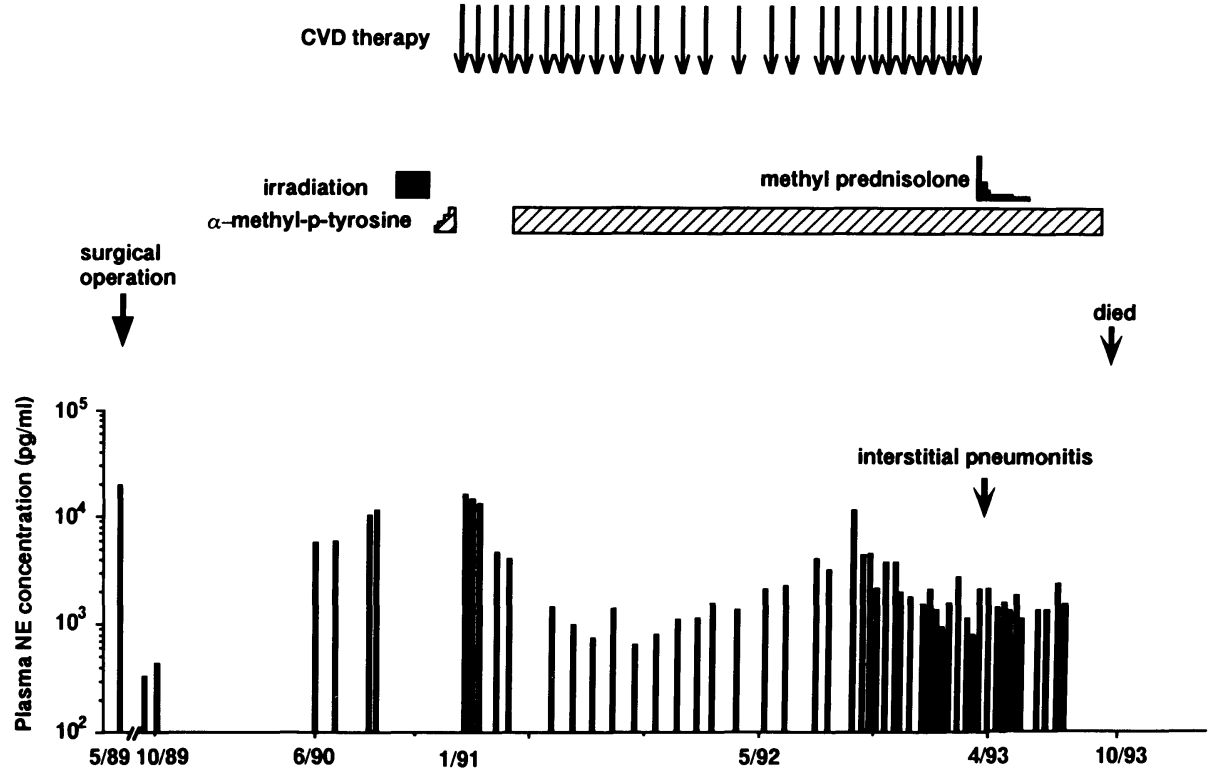

Fig. 1. Clinical course of case 1. Numbers along the bottom are the month and year. NE, norepinephrine; CVD, a combined chemotherapy with cyclophosphamide, vincristine and dacarbazine.

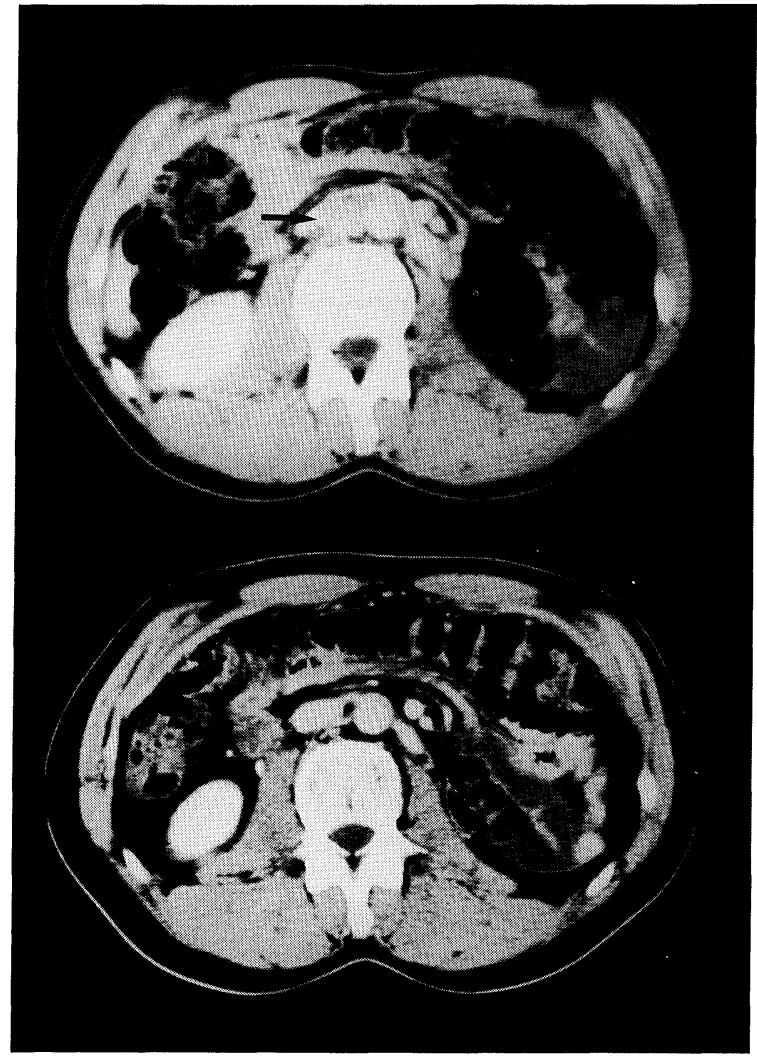

Fig. 2. CT scans of abdomen in case 1 (top) before chemotherapy $(7 / 90)$ and (bottom) after eight cycles $(8 / 91)$. Note disappearance of a paraaortic adenopathy (arrow in top). moved in May 1989. At preoperative examinations, computerized tomographic (CT) scans of the brain, thorax and abdomen as well as scintigraphy of the bone did not show any signs of its metastases. Plasma norepinephrine (NE) levels returned to the normal range after surgical removal of the tumor. He remained well until June, 1990 when he noted palpitation, sweating and tenderness at the lower part of the sternum. Blood pressure was mildly elevated and plasma catecholamine levels were noticeably elevated. He was suspected of having recurrent pheochromocytoma and then referred to our hospital. The plasma NE level on admission was high at $11000 \mathrm{pg} / \mathrm{ml}$ (normal, up to $250 \mathrm{pg} / \mathrm{ml}$ ). CT scans showed an adenopathy in the paraaortic region (Fig. 2). A sectional rentogenography of the sternum showed an osteolytic region.

He was given a course of irradiation (60 Gy over 6 weeks) to the osteolytic area of the sternum, and the osteolytic area became smaller and his tenderness at the sternum disappeared. His blood pressure and heart rate were under better control with doxazosin, $6 \mathrm{mg} /$ day, and $\alpha$-methyl- $p$-tyrosine, a catecholamine synthesis inhibitor, 1000 $\mathrm{mg} /$ day, but urinary NE and vanillylmandelic acid levels remained noticeably high.

In January, 1991 the patient began treatment with 
CVD regimen which consisted of intravenous administration of cyclophosphamide, $750 \mathrm{mg} / \mathrm{m}^{2}$ on day 1 , vincristine or vindesine, $1.4 \mathrm{mg} / \mathrm{m}^{2}$ on day 1 , and dacarbazine $600 \mathrm{mg} / \mathrm{m}^{2}$ on days 1 and 2 , in 21- to 28-day cycles [14]. By the end of the third cycle of the chemotherapy, he became asymptomatic and there was significant regression of the paraaortic tumors and reduction of urinary catecholamines. After 4 cycles of the CVD regimen he was discharged from the hospital but continued to receive this treatment at the outpatient clinic every 3 to 4 weeks. After 8 cycles of the chemotherapy, radiological studies showed no evidence of the disease within the abdomen (Fig. 2), but plasma NE $(730 \mathrm{pg} / \mathrm{ml})$ did not fall to the normal range. He had myelosuppression with a slight reduction in erythrocyte and leukocyte counts as a side effect of this treatment, but this was tolerable and reversible.

The patient remained asymptomatic until the 16th cycle of the chemotherapy in May, 1992, when plasma NE was high $(2000 \mathrm{pg} / \mathrm{ml})$. Two months later, a CT scan of the abdomen showed recurrent retroperitoneal tumors. The tumors were progressing rapidly in spite of the CVD regimen. The combination therapy was discontinued because he had an episode of severe interstitial pneumonitis, probably due to the side effect of the chemotherapy and/or radiation, that responded to high doses of methylprednisolone. Although he did not have any severe signs and symptoms due to the catecholamine excess, his condition continued to worsen because of the rapid growth of the tumors and he died in October, 1993.

\section{Case 2}

In 1988, a 35-year-old man was referred for evaluation of fever of unknown origin. A CT scan showed a left adrenal mass and ${ }^{131}$ I-MIBG scintigraphy demonstrated a distinct accumulation of the isotope over the left adrenal gland. Plasma and urinary catecholamine levels were very high, and we diagnosed left adrenal pheochromocytoma and surgical exploration was performed. On microscopic examination, these pheochromocytoma cells did not have any features of malignancy.

He became asymptomatic after surgical removal of the tumor and plasma catecholamine levels remained normal until October, 1992 when pulmonary nodules were seen on x-ray films. Although a CT

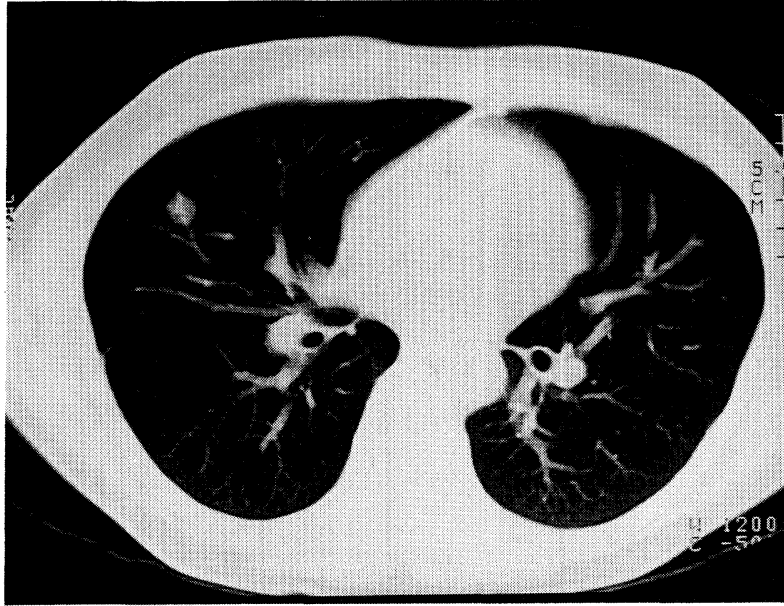

Fig. 3. CT scan of lungs in case 2 before chemotherapy (1/92).

scan showed multiple masses in the lungs (Fig. 3), he remained asymptomatic and the plasma NE level was up only slightly $(350 \mathrm{pg} / \mathrm{ml})$ and plasma epinephrine was $71 \mathrm{pg} / \mathrm{ml}$ (normal, up to $100 \mathrm{pg}$ / $\mathrm{ml}$ ). In February, 1993 a lung biopsy specimen showed metastatic pheochromocytoma. Informed consent was obtained from the patient, and the decision was then made to give him our proposed CVD regimen for 5 cycles. After the third cycle of the chemotherapy, plasma NE returned to normal (160-180 pg/ml, Fig. 4). There was slight regression in the size (about 10\%) of pulmonary nodules on CT scan. The patient had mild reversible erythrocytopenia and granulocytopenia, which was controlled without any medication.

He has not been treated with the CVD regimen since August, 1993, but metastatic pheochromocytomas in the lung have not increased in size and plasma catecholamine levels remain normal, and he continues to feel well and leads a full and active life.

\section{Discussion}

Malignant pheochromocytoma is an uncommon tumor which accounts for 10-20\% of all cases of pheochromocytoma [1-4, 15]. The diagnosis of a malignant pheochromocytoma cannot be accurately determined by histologic findings and is instead depend on distant metastasis which occurs at a site where chromaffin tissue is not otherwise found, such as lymph nodes, liver, bones, or lungs [16]. 


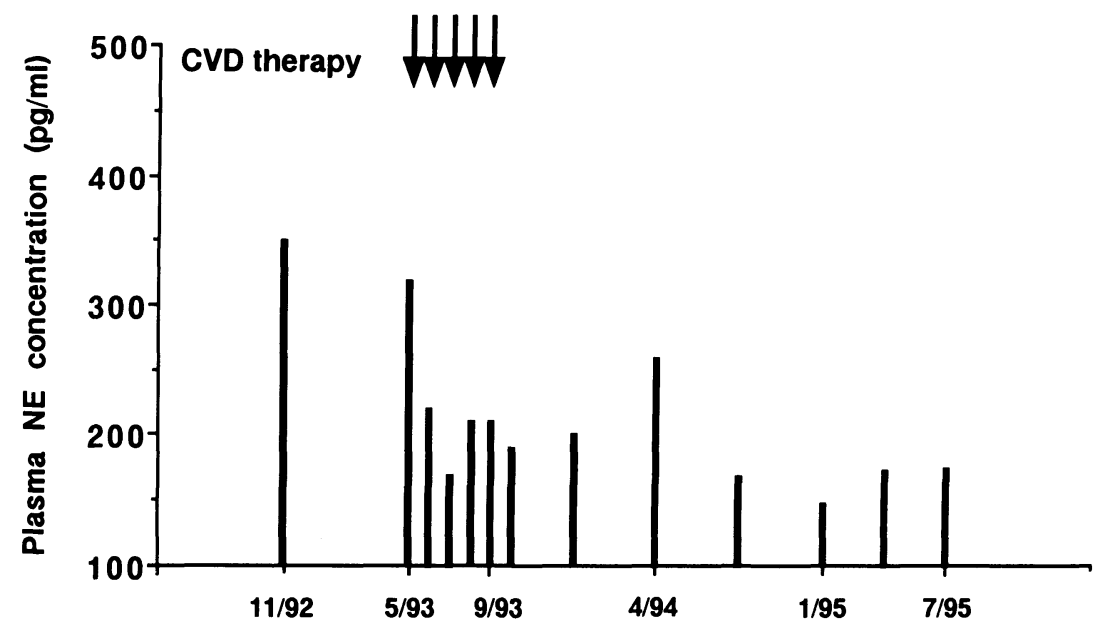

Fig. 4. Time course of plasma norepinephrine concentration in case 2. Numbers along the bottom are the month and year. NE, norepinephrine; CVD, a combined chemotherapy with cyclophosphamide, vincristine and dacarbazine.

Various conventional chemotherapy regimens have been used and had little effect $[9,15,17]$, and the mean 5-year survival rate is only about $40 \%$ [15].

Recently, however, Averbuch et al. [11] reported that a combination chemotherapy with CVD in 14 patients with malignant pheochromocytoma induced a tumor response in $57 \%$ and a hormonal response in $79 \%$. This CVD regimen was also effective in our two cases. According to the criteria of patient's responses to therapy by Averbuch et al. [11], our case 1 showed a complete tumor response and a partial hormonal response although these effects were temporary, and our case 2 showed a slight but apparent hormonal response but no change in tumor response as they defined less than a $25 \%$ decrease in tumor size as "no change". Sato et al. [18] have reported that the CVD regimen was effective in $11(78.6 \%)$ out of 14 malignant pheochromocytoma, including our case 1. Because malignant pheochromocytoma is a rare tumor, survival data relating to patients with malignant pheochromocytoma have not been reported since the CVD regimen was applied to this disease [19-21].

As malignant pheochromocytoma often grows relatively slow [22], one might speculate that the prognoses of the present two cases could have been the same as they were or even better if they had not been treated with CVD therapy. We cannot confirm this sort of speculation. Further controlled study is necessary to answer this question.

Adverse effects of the CVD therapy have been reported to be mild and well tolerated [11]. Reversible myelosuppression, and neurologic and gastrointestinal side effects are commonly seen. In our two cases, reversible granulocytopenia and erythrocytopenia were seen without significant sequential complications. Since our case 1 had severe interstitial pneumonitis which responded promptly to therapy with methyl prednisolone, the CVD regimen had to be discontinued. The cause of the interstitial pneumonitis in our case 1 was thought to the side effects of the CVD regimen and/or radiation.

${ }^{131}$ I-MIBG therapy $[6,7]$ is another newly developed treatment for malignant pheochromocytoma. Krempf et al. [7] reported that treatment with ${ }^{131}$ IMIBG was effective in 9 out of 15 patients with malignant pheochromocytoma. These results are close to those observed with CVD therapy reported by Averbuch [11]. This ${ }^{131}$ I-MIBG therapy is necessary for radiotherapeutic facilities, whereas CVD therapy can be used in any hospital. Since response to therapy, whether with chemotherapy or ${ }^{131} \mathrm{I}-\mathrm{MIBG}$, is variable, it is difficult to determine the factor(s) or clinical features which can anticipate the effectiveness of chemotherapy or ${ }^{131}$ I-MIBG radiotherapy. Comparative studies or associated treatments need to be investigated.

Plasma catecholamine concentrations were high 
before clinical symptoms appeared in our case 1 , and decreased in response to CVD therapy in our two cases, in parallel with improving clinical signs and symptoms. Averbuch et al. [11] evaluated patient responses to CVD therapy on the basis of the drop in catecholamine levels. A serial measurement of plasma and urinary catecholamines may therefore be useful for early detection of recurrence of pheochromocytoma and for evaluation of the effectiveness of chemotherapy.

In conclusion, two patients with malignant pheochromocytoma treated with the CVD regimen combination chemotherapy were reported. This chemotherapy appears to be effective for advanced malignant pheochromocytoma.

\section{References}

1. Brennan M, MacDonald J (1985) Cancer of the endocrine system. In: DeVita VT, Rosenberg SA, Hellman S (eds) Cancer: Principles and Practice of Oncology. JB Lippincott Co., Philadelphia, 11791241.

2. Manger WM, Gifford RW, Jr (1977) Malignant pheochromocytoma. In: Manger WM, Gifford RW, Jr (eds) Pheochromocytoma. Springer-Verlag, New York, 63-84.

3. Miura Y, Ishizuka Y, Sugawara T (1986) A survey for malignant pheochromocytoma in Japan. In: Takeda R (chairman) Annual Report of Health and Welfare "Disorders of adrenal hormones" Research Committee, Japan: 308-319 (In Japanese).

4. Takeda R, Yasuhara S, Miyamori Y, Sato T, Miura $Y$ (1986) Phaeochromocytoma in Japan: Analysis of 493 cases during 1973-1982. J Hypertens 4 (Suppl 5): S397-S399.

5. Shapiro B, Sisson JC, Wieland DM, Manger TJ, Zempel SM, Mudgett E, Gross MD, Carey JE, Zasadny KR, Beierwaltes WH (1991) Radiopharmaceutical therapy of malignant pheochromocytoma with [131]] metaiodobenzylguanidine: Results from 10 years of experience. J Nucl Biol Med 35: 269-276.

6. Sisson JC, Shapiro B, Beierwaltes WH, Glowniak JV, Nakajo M, Mangner TJ, Carey JE, Swanson DP, Copp JE, Satterlee WG, Wieland DM (1984) Radiopharmaceutical treatment of malignant pheochromocytoma. J Nucl Med 24: 197-206.

7. Krempf M, Lumbroso J, Mornex R, Brendel AJ, Wemeau JL, Delisle MJ, Aubert B, Carpentier P, Fleury-Goyon MC, Gibolt C (1991) Treatment of malignant pheochromocytoma with [ ${ }^{131}$ I]metaiodobenzylguanidine: A French multicenter study. J Nucl Biol Med 35: 284-287.

8. Scott HW, Reynolds V, Green W, Page D, Oates JA, Robertson D (1982) Clinical experience with malignant pheochromocytomas. Surg Gynecol Obstet 154: 801-818.

9. Drasin H (1978) Treatment of malignant pheochromocytoma. West J Med 128: 106-111.

10. Feldman JM (1983) Treatment of metastatic pheochromocytoma with streptozocin. Arch Intern
Med 143: 1799-1800.

11. Averbuch SD, Steakley CS, Young RC, Gelmann EP, Goldstein DS, Stull R, Keiser HR (1988) Malignant pheochromocytoma: Effective treatment with a combination of cyclophosphamide, vincristine, and dacarbazine. Ann Intern Med 109: 267-273.

12. Finklestein JZ, Klemperer MR, Evans A, Bernstein I, Leikin S, McCreadie S, Grosfeld J, Hittle R, Weiner J, Sather H, Hammond D (1979) Multiagent chemotherapy for children with metastatic neuroblastoma: A report from Children's Cancer Study Group. Med Pediatr Oncol 6: 179-188.

13. Dosik GM, Rodriguez V, Benjamin RS, Bodey GP (1978) Neuroblastoma in the adult: Effective combination chemotherapy. Cancer 41: 56-63.

14. Keiser HR, Goldstein DS, Wade JL, Douglas FL, Averbuch SD (1985) Treatment of malignant pheochromocytoma with combination chemotherapy. Hypertension 7 [Suppl I]: I-18-I-24.

15. Van Heerden J, Sheps S, Hamberger B, Sheedy P, Paston J, Remine W (1982) Pheochromocytoma: Current status and changing trends. Surgery 91: 367-373.

16. Shapiro B, Sisson J, Lloyd B, Nakajo M, Satterlee W, Beierwaltes W (1984) Malignant pheochromocytoma: Clinical biochemical and scintigraphic characterization. Clin Endocrinol 20: 189-204.

17. Brennan M, Keiser H (1982) Persistent and recurrent pheochromocytoma. World J Surg 6: 397-401.

18. Sato T (1993) Malignant pheochromocytoma in Japan. In: Saruta T (chairman) Annual Report of Health and Welfare "Disorders of adrenal hormones" Research Committee, Japan: 55-66 (In Japanese).

19. Schlumberger $M$, Gicquel C, Lumbroso J, Tenenbaum E, Comoy E, Bosq J, Fonseca E, Ghillani PP, Aubert B, Travagli JP, Gardet P, Parmentier C (1992) Malignant pheochromocytoma: Clinical, biological, histologic and therapeutic data in a series of 20 patients with distant metastases. J Endocrinol Invest 15: 631-642.

20. Mornex R, Badet C, Peyrin L (1992) Malignant pheochromocytoma: A series of 14 cases observed 
between 1966 and 1990. J Endocrinol Invest 15: 643649.

21. Mizuno O (1994) A case of malignant pheochromocytoma treated with a combination of cyclophosphamide, vincristine, and dacarbazine (CVD): A review of the Japanese literature of malignant pheochromocytoma treated with a combination of CVD. Folia Endocrinol 70: 1039-1046 (In Japanese)

22. Kaplan NM (1994) Pheochromocytoma (with a preface about incidental adrenal masses). In: Kaplan NM (ed) Clinical Hypertension. Williams \& Wilkins, Baltimore, 367-387. 